\title{
Seed Borne Fungal Organisms Associated with Germination Success of Terminalia brownii (Fresen) in Kenya
}

\author{
Jackline Atieno ${ }^{1 *}$, Gilbert O. Obwoyere ${ }^{1 *}$, Dickson L. Makanji ${ }^{1}$, Michael M. Okeyo² \\ ${ }^{1}$ Egerton University, Njoro, Kenya \\ ${ }^{2}$ Dryland Eco-Region Research Programme, Kibwezi, Kenya \\ Email: ^atienojacky26@yahoo.com
}

How to cite this paper: Atieno, J., Obwoyere, G. O., Makanji, D. L., \& Okeyo, M. M. (2021). Seed Borne Fungal Organisms Associated with Germination Success of Terminalia brownii (Fresen) in Kenya. Open Journal of Forestry, 11, 341-351. https://doi.org/10.4236/ojf.2021.114021

Received: June 2, 2021

Accepted: September 21, 2021

Published: September 24, 2021

Copyright $\odot 2021$ by author(s) and Scientific Research Publishing Inc. This work is licensed under the Creative Commons Attribution International License (CC BY 4.0).

http://creativecommons.org/licenses/by/4.0/

\begin{abstract}
Terminalia brownii is an indigenous tree species highly valued in the Kenyan drylands for its products such as timber for wood curving, medicine, and charcoal production, among others. Due to this high value followed by overutilization, its population in the drylands is dwindling. Concern about the species' low regeneration as shown by low germination has been raised. This research was conducted on the seed borne fungal organisms that are associating with the germination of this species. T. brownii seeds were collected from cluster patches of the species in Kendu Bay, Kimose and Ndumoni in Homabay, Baringo and Kitui counties of Kenya respectively. The seeds were harvested for fruit probing for maturity confirmation. Random sampling was used in selecting thirty trees, 50 meters apart, from which fresh fruits were uniformly collected from the crowns. The research adopted a complete block experimental design where one hundred seeds each from the three sites, were subjected to a germination test, seed borne fungal organisms' presence, identified organisms cultured and DNA and DNA sequencing carried out for identification. Fungal organisms associated with germination success of $T$. brownii were Fusarium equiseti, Pestalotia sp, and Alternaria alternata. Paired $\mathrm{t}$ test run between germinants versus the number of sown seeds gave $\mathrm{N}$ $=12$, $p$-value of $0.000, t=16.29$. On the other hand, paired $\mathrm{t}$ test run between fungal infected seeds with the number of germinants gave $\mathrm{N}=12, p-0.000, t=$ -8.78. Fungi associated with germinants included Penicillium sp, and the data analyzed using Mann-Whitney $U$ test run showed significant difference at a $\mathrm{p}$ value of 0.000 . Identified organisms associating with none germination and germination success on the other hand were analyzed using descriptive analysis. Fungal organisms associating with germination success of $T$. brownii significantly affect germination of freshly extracted seeds from the field,
\end{abstract}


hence, for maximum germination achievement, seeds should be sown while still fresh.

\section{Keywords}

Seed Borne Fungal Organisms, Germination Success, Terminalia brownii

\section{Introduction}

Terminalia brownii is one of indigenous tree species in Kenya in the Combretaceae family, which comprises of more than 200 species. Trees in this family are distributed throughout the tropical and sub-tropical regions of the world. Approximately fifty species of Terminalia are naturally distributed throughout western, eastern, and southern Africa. These species, which are semi-deciduous range from small shrubs or trees to large deciduous forest trees (Beentje et al., 1994; Gibreel et al., 2013). Tree species heights in terminalia genus range $20 \mathrm{~m}$ to $30 \mathrm{~m}$ high with dense crown and somewhat layered crown with drooping foliage.

Many terminalia species are drought tolerant and occur in woodlands, bush lands, and wooded savannah within arid and semi-arid regions. They are also found more often along river valleys in dry areas. Terminalia genera include several indigenous trees and shrubs mainly in Africa, such as T. brownii, T. spinosa, T. prunioides, T. kilimandscharica and T. mollis, from East Africa; T. superba and T. ivorensis from West Africa and T. catappa which is cultivated in coastal areas as an ornamental (Beentje et al., 1994). T. brownii, is native to Eritrea, Ethiopia, Kenya, Somalia, Sudan, Tanzania, and Uganda. These species have their own important roles in the ecosystem as a species and generally as a tree providing the various ecosystem services and products.

Despite the importances of the species, Terminalia seeds have in the past been reported to heavily be infested by disease causing organisms (Mosango, 2013) hence alarming concern on its regeneration. For example, seeds collected from Kitui were reported to be highly infested by insects (Mosango, 2013), while those from other drylands of Kenya have not been researched on. As such, there has been a need to work on ways of promoting propagation of $T$. brownii before it becomes threatened or endangered. Little research has been done on disease causing organisms that are attacking the species in the field. Consequently, Terminalia continues to exhibit poor germination percentage and is on the verge of becoming threatened. Therefore, this study sought to establish if fungal organisms affect the germination of Terminalia brownii seeds and the emergence of the seedlings.

There are reported efforts that have been geared towards conservation of this species that include on farm planting in Uganda as it is a good agroforestry tree (Okullo \& Waithum. 2007), sections with Terminalia species have received protected area status under Yemen law (Hall et al., 2008). T. brownii species are also 
being used in rehabilitation of dry lands (Kitalyi et al., 2002) in West Pokot, Kenya. The species are left on land during habitat conversion into agricultural lands, mainly because of the medicinal value (Njoroge et al., 2010), In Ethiopia, the species is being afforded the highest conservation in Babile elephant sanctuary (Belayneh et al., 2011), and it is also being conserved in a programme dealing with synergizing conservation and adaptation to climate change in Kitui, (Eriksen et al., 2006).

\subsection{Factors Affecting Seed Viability}

A seed can be rendered not viable when it is still in its dormancy period or is dead. Dormancy could be either endogenous meaning it originate from inside, and related to the seed embryo, or exogenous dormancy which is related to seed coat or tissues surrounding seed coat. Endogenous be could as a result of physiological or morphological conditions of seed embryo, or both. Exogenous dormancy on the other side could be because of physical, chemical, or mechanical characteristics of the seed coat (Fraedrich, 2001).

A seed can also be rendered dead because of bacterial or fungal disease infection. This is explained by a pathogen establishing itself on and inside seeds during the development of the seed, hence competing for nutrients and destroying vital plant parts. The infections by the fungi could be 1) by the destruction of the petals of flowers, thus interfering with pollination, 2) during fertilization where the pathogens destroy the male and female parts of the flowers, 3) after final fruit production while still on the tree or when it falls onto the ground with the fungi inoculum, 4) and during collection, processing, transit, and storage (Gure et al., 2004).

There are a variety of seed-borne pathogens which include: virus, bacteria, nematode, and fungi. Pathogenic fungi are classified as those that infect seeds internally and destroy the endosperm and the embryo, or those fungi that contaminate the seeds and affect seedling germination and development. Some of the seed-borne fungi are Aspergillus spp., Mucor spp., Penicillium spp., Rhizopus spp., and Trichoderma spp which have been reported to be reducing germination of conifers in some laboratory tests (Fraedrich, 2001). Research on disease-causing organisms that could be affecting germination of $T$. brownii seeds has not been carried out, except for those associating with its floral phenology (Okeyo et al., 2019).

\subsection{Site Description}

The seeds were collected in three selected provenances which are from Ndumoni in Kitui, Kimose in Baringo and Gendia in Homa Bay Counties (Figure 1). The sites represent distinct ecological regions where the species is naturally distributed in Kenyan dry lands (Beentje et al., 1994).

Ndumoni is in Kyangwithia East location of Kitui Central sub-County within Kitui County at a latitude of $0.97^{\circ} \mathrm{S}$ and longitude of $37.47^{\circ} \mathrm{E}$ in Eastern Kenya, 


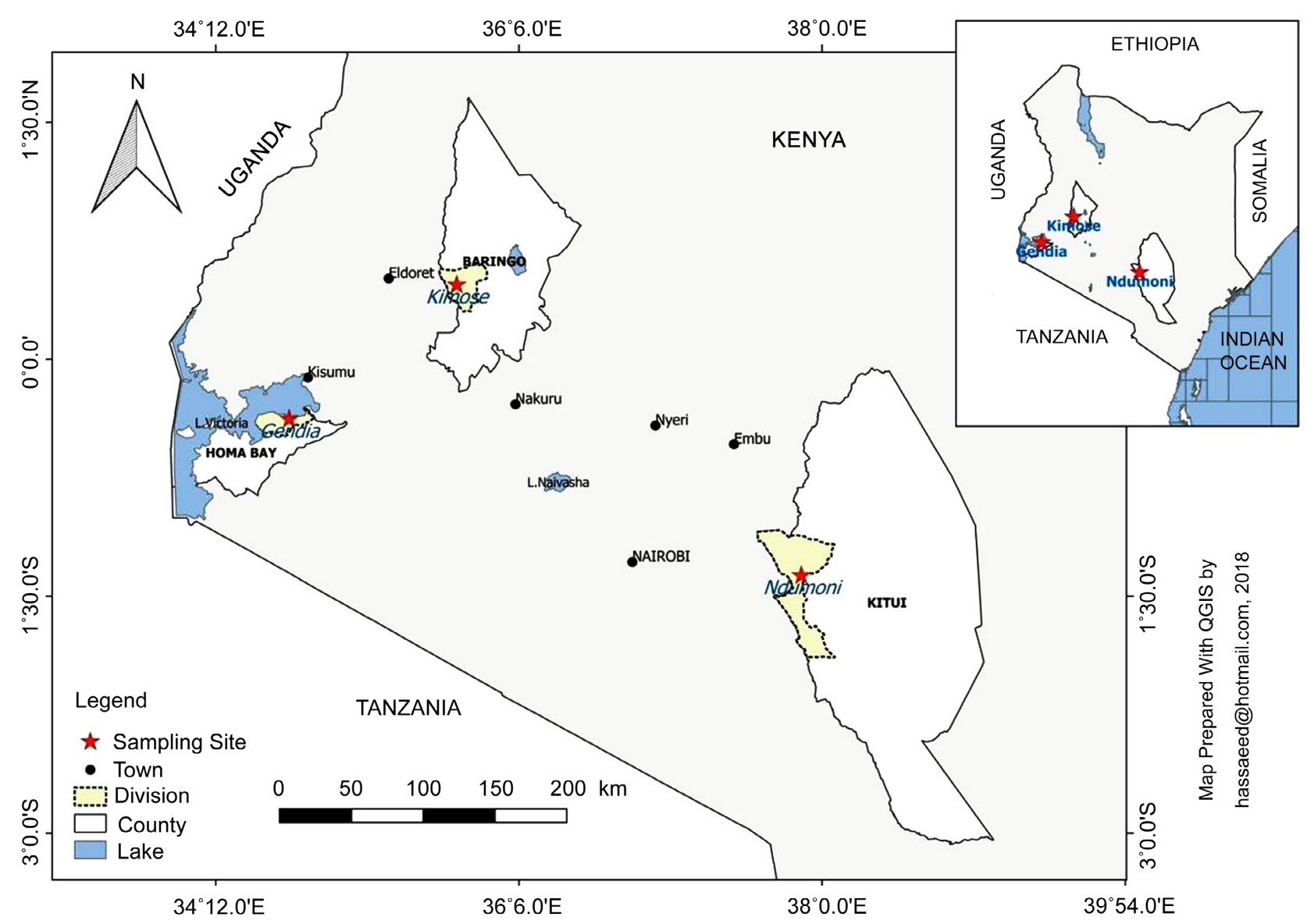

Figure 1. Map showing sites T. brownii seeds samples collection sites.

while Kimose is in Kimose location of Mogotio Sub County within Baringo County at a Latitude of $0.47^{\circ} \mathrm{N}$ and Longitude of $35.71^{\circ} \mathrm{E}$ in the Rift Valley. Kendu Bay is in North Karachuonyo location of Karachuonyo sub-County within Homa Bay County at a latitude of $0.38^{\circ} \mathrm{S}$ and longitude of $34.66^{\circ} \mathrm{E}$ within the Lake Victoria Basin. Topography varies from well undulating land at Ndumoni in Kitui and Gendia in Kendu Bay to small hills with rocky outcrops at Kimose in Baringo. Average altitude for Ndumoni, Kimose, and Gendia are 1141, 1563 and $1217 \mathrm{~m}$ above sea level, respectively.

\section{Methodology}

Sections of patches of $T$. brownii trees where they were in high numbers were chosen. Fruits were first probed to confirm their maturity, after which thirty trees which were 50 meters apart were selected and samples collected uniformly from their crowns (Luna \& Wilkinson, 2009).

\subsection{Research Design}

The research adopted a complete random experimental design where one hundred seeds each from the different lots collected from the three sites, i.e., Kimose, Kendu Bay and Ndumoni, were soaked in cold water for 24 hours and 
then incubated in moistened filter paper. They were placed in groups of twenty-five of 4 replicates per provenance, each with its control of Senna siamea as shown in Plate 1. These samples were then transferred to an incubator.

\subsection{Germination Test}

Extracted seeds from the collected fruits each of one hundred seeds from the three sites, giving us a total of three hundred, were soaked in cold water for 12 hours in different containers per site. The seeds were then plated distantly on moistened filter papers inside petri dishes, in groups of twenty-five each by site and incubated at a temperature of $30^{\circ} \mathrm{C}$. Monitoring followed for developments which were then recorded for some seeds from the third day. The seeds were considered to have germinated only upon radicle protrusion of visible $2 \mathrm{~mm}$ plumule (ISTA, 2004), as shown in Plate 2, and their numbers recorded.

\subsection{Evaluation of Seeds That Germinated}

First signs of germination of $T$. brownii which was protrusion of the radicle were observed in some of the seeds on the fifth day. Terminalia brownii seeds were considered to have germinated on protrusion of radicle and plumule, as shown in Plate 3. Germinants were counted and recorded, together with the numbers of those that had not produced plumule after protrusion of the radicle.

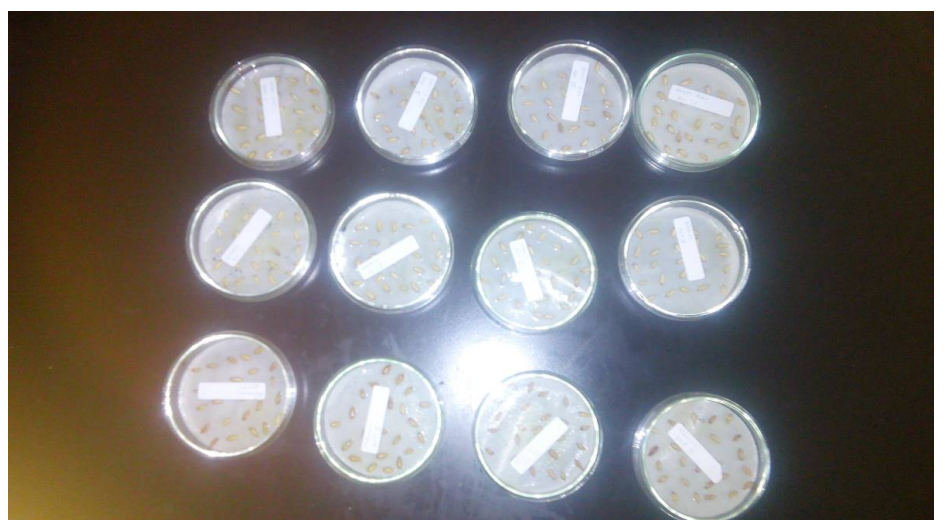

Plate 1. Germination seeds test arrangement in groups of 25, on moistened filter paper.

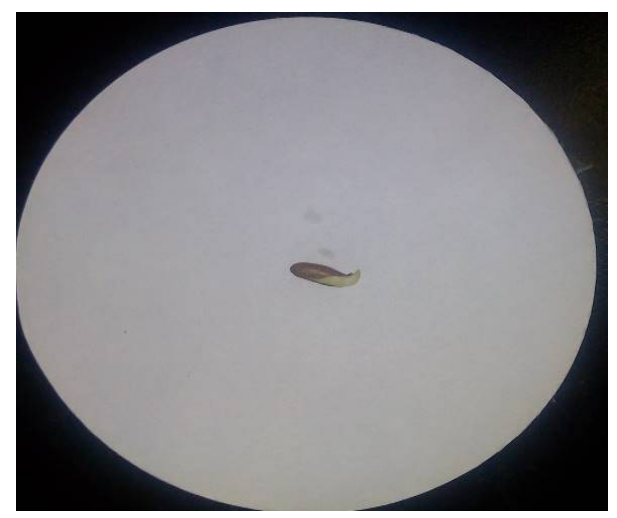

Plate 2. Germinated T. brownii seed. 


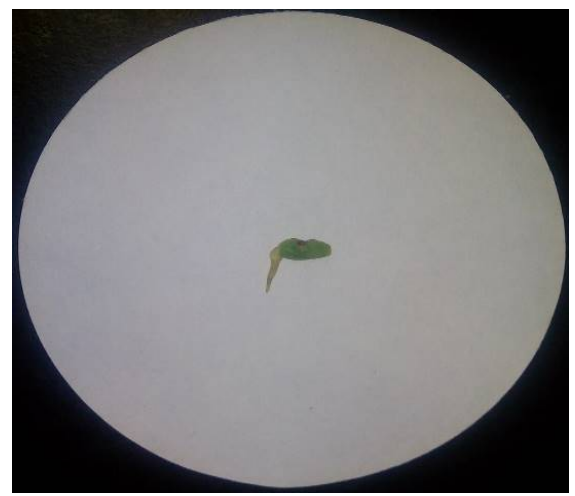

Plate 3. Fully germinated T. brownii seed showing both plumule and radical.

\subsection{Fungal Pathogens Identification}

Terminalia brownii seeds that did not germinate and those that germinated were washed with distilled water, then sterilized using $2 \%$ hypo chloric acid to do away with contaminants. The seeds were plated on malt agar per the replicates and sites, and the agar was treated with $0.1 \%$ of steptomycellia antibiotic to suppress bacterial organisms' growth which could hinder the growth of fungi. All these were done in a hood, thus no external factor got into the dishes. The samples were then incubated at $\pm 28^{\circ} \mathrm{C}$. By the fourth day the fungal organisms had grown, which were identified at genus level using cultural, morphological, and biochemical characteristics. Colonies showing typical fungal characteristics were sub-cultured on MEA until pure cultures were obtained. The pure cultures were preserved in MEA slants at $4^{\circ} \mathrm{C}$ and glycerol for the next process of DNA extraction. Filaments of the grown fungal organisms' colonies associated with germination were extracted and used in DNA analysis. The process involved DNA extraction, amplification, and sequencing.

\section{Results}

Performance of $T$. browniis seeds germination was determined by noting the numbers that germinated from the sown lots. T. brownii seeds were subjected to a germination test and the number of seeds that did not germinate recorded. Percentages derived from the samples were as shown in Table 1.

Data of the number of seeds that did not germinate were subjected to normality test which tested normal $(\mathrm{N}=12, p=0.063)$. One sample t-test was run between the numbers of none germinated seeds against 25 to test for significant change in terms of germination, and this gave $(\mathrm{N}=12, p$ value $=0.000, t$ $=-16.29)$. This therefore shows that there is evidence to suggest that there is significant difference between the number of none germinated seeds versus the number of seeds sown which was 25 , meaning that a significant number did not germinate.

Second group of data of the infected seeds was also subjected to normality test and gave $(\mathrm{N}=12, p=0.149)$. Paired sample $\mathrm{t}$ test was performed on the number of none germinated seeds versus fungal infected seeds (Table 2) which were the 
Table 1. Germination percentages of T. brownii seeds in the experiment.

\begin{tabular}{cccccc}
\hline \multirow{2}{*}{ Site } & \multicolumn{5}{c}{ Germination percentages } \\
\cline { 2 - 6 } & $\mathbf{1}^{\text {st }}$ Replicate & $\mathbf{2}^{\text {nd }}$ Replicate & $\mathbf{3}^{\text {rd }}$ Replicate & $\mathbf{4}^{\text {th }}$ Replicate & Average \\
\hline Gendia (Kendu Bay) & $68 \%$ & $68 \%$ & $68 \%$ & $60 \%$ & $66 \%$ \\
Kimose (Baringo) & $56 \%$ & $60 \%$ & $56 \%$ & $32 \%$ & $51 \%$ \\
Ndumoni (Kitui) & $64 \%$ & $72 \%$ & $52 \%$ & $80 \%$ & $67 \%$ \\
\hline
\end{tabular}

Table 2. Number of T. brownii seeds that did not germinate versus number of fungal infested seeds.

\begin{tabular}{ccc}
\hline Site & No. of seeds that did not germinate & No. of fungal infested seeds \\
\hline Gendia & 8 & 2 \\
Gendia & 8 & 0 \\
Gendia & 9 & 0 \\
Gendia & 10 & 3 \\
Kimose & 13 & 1 \\
Kimose & 9 & 1 \\
Kimose & 12 & 3 \\
Kimose & 18 & 1 \\
Ndumoni & 9 & 3 \\
Ndumoni & 9 & 2 \\
Ndumoni & 12 & 1 \\
Ndumoni & 6 & 2 \\
\hline
\end{tabular}

main variables in this objective giving a result of $(\mathrm{N}=12, p$ value $=0.000, t$ value $=-8.78)$. This therefore shows that there is evidence to suggest there is no significant difference between the data of the two variables, in that the fungal organisms did not affect germination significantly.

The evidence therefore confirms that fungal organisms identified did not contribute in a bigger percentage to registered germination failure. Seed borne fungal organisms associated with germination failure of $T$. brownii as identified in this experiment were mainly Alternaria $s p(47.40 \%)$ Fusarium $s p(42.10 \%)$ and Pestalotia sp (10.50\%).

Data of the number of germinants on the other hand was normal $(\mathrm{N}=12$, $p$-value $=0.063)$. Data of the number of fungal infected germinants was not normal $(\mathrm{N}=12, p$ value $<0.005)$ and thus were analyzed using non-parametric test of Mann-Whitney $U$ test of null hypothesis test stating that the two were not equal. The results showed that the test was significant at 0.000 and thus suggest that there is a relation between the two variables. Identified fungal organisms therefore associated with a lot of the germinants but did not contribute greatly to progressive germination of the seeds. Seed borne fungal organisms associated with germination of T. brownii as identified were mainly Penicillium. Identified infectious seed borne fungal organisms were Fusarium equiseti and Alternaria alternata among other identified organisms as shown in Figure 2. 


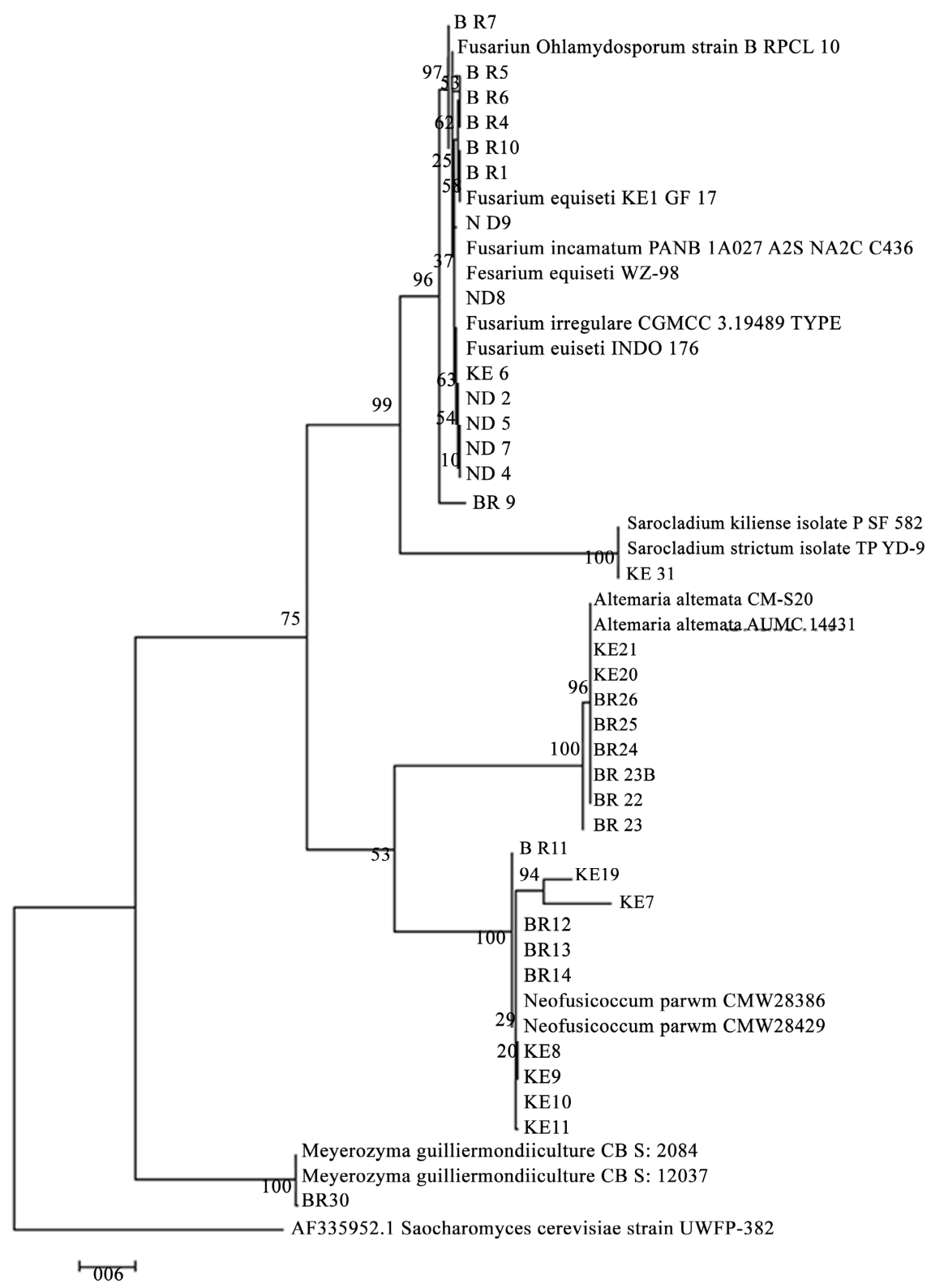

Figure 2. Sequenced DNA samples of fungal organisms associating with T. brownii germination success.

\section{Discussion}

Terminalia brownii seeds germination test in this research displayed significant difference between the sown seeds and germinants meaning significant number did not germinate. This confirms the various sources of seed germination failure which could be seed's exogenous or endogenous factors. Endogenous factor could be physiological or morphological condition of the embryo or both and leaving exogenous factors of chemical physical and mechanical characteristics out of question as the seeds were treated by soaking in water.

There was a significant difference recorded in $T$. brownii seeds that failed to germinate and those that germinated successfully, though the difference was not 
contributed to by the identified fungal organisms thus confirming the specific association of the identified seed borne fungal where they affect the seeds at different stages. This is confirmed by research done by Fraedrich (2001) and Gure et al., (2005) where they found that there are seed borne fungal organisms that destroy the young plant by competing for the food reserves for the young embryo which is to be used during the initial stages of the development.

Seed borne fungi identified in this study to be associating with germination success of T. brownii is Penicillium. This agrees with the results of a study done by Khatun, Shamsi and Bashar (2018), in which seed germination was affected by Aspergillus niger, Aspergillus flavus, Chaetomium globosum, Penicillium sp, Rhizopus stolonifera, and Aspergillus fumigatus. An interesting finding about this is that the prevalence in seed also increases directly with increase in storage time unlike for some seed borne diseases such as Syncephalastrum recemosum.

Some pathogens are very dangerous in that they can penetrate seed wall and infect the seeds from the internal side by destroying the embryo and endosperm like in the case of fusarium and Penicillin expansum (Franke et al., 2014, Lezcano et al., 2015) Once they destroy the endosperm, the effect is felt on germination process where if extreme, damages on the endosperm leads to total loss of germination as the embryo won't find sources of energy for its growth. Pathogens sometimes affect the seed by affecting the germination upon initiation of germination as is in the case of Fusarium tricintum and Aspergillus flava (Franke et al., 2014, Lezcano et al., 2015). These therefore indicates clearly that some seed borne fungi attacks seeds after germination initiation, where they attack the radicle mainly, and thus can be controlled by doing away with them from the coat. While some serious ones like fusarium, reported to be internal fungus originating from within the seed, destroy the seed completely leaving them with no signs of germination at all. Such studies on the effect of seed borne fungi on germination failure and germination of seeds have been confirmed in germination of grains which subsequently led to reduction in seedling growth vigour and reduced germination percentages (Tsedaley, 2015).

\section{Conclusion}

Freshly harvested T. brownii still faced challenges in achieving a hundred percentage according to this research's first objective results. Secondly, Seed borne fungi identified to be associated with the T. brownii seeds that failed to germinate did not significantly affect the seeds' germination. However, according to related studies on similar fungi identified in this study, effects of the fungi would have been realized if they infested many seeds. Thirdly, seed borne fungi found on the germinants do not interfere with seeds' germination. And lastly, out of the identified fungi, most dangerous seed borne fungi to germination is Fusarium equiseti and Alternaria alternata.

\section{Recommendation}

Internal seed borne fungal organisms as per the effect of Fusarium equiseti need 
to be addressed earlier before storing the seeds, followed by relevant external seed fungicide for the organisms which wait for emergence of the embryo. Secondly, propagation of tree species by seeds needs a keen monitoring at the earlier stages of the establishment in which seed borne, reported to be soil borne too, greatly influences the stage. This can be achieved by dressing the seeds with the appropriate fungicide, with respect to the pathogen causing the disease infection in specific cases. Thirdly, fungicides specific for Fusarium equiseti need to be invented. On the other hand, if anti-pathogenic strains of these fungi can be discovered, they can be applied to the soil during planting.

\section{Acknowledgements}

My appreciation goes to my supervisors at Egerton University supervisor for the guidance in this research, RUFORUM through TagDev for partial financial support in my research project, Mr. Joseph Machua and Priscilla Kimani who are Kefri staff for their help in the project.

\section{Conflicts of Interest}

The authors declare no conflicts of interest regarding the publication of this paper.

\section{References}

Beentje, H., Adamson, J., \& Bhanderi, D. (1994). Kenya Trees, Shrubs, and Lianas. National Museums of Kenya.

Belayneh, A., Bekele, T., \& Demissew, S. (2011). The Natural Vegetation of Babile Elephant Sanctuary, Eastern Ethiopia: Implications for Biodiversity Conservation. Ethiopian Journal of Biological Sciences, 10, 137-152.

Eriksen, S., Gachathi, F. N., Muok, B., Ochieng, B., \& Owuor, B. (2006). Synergies in Biodiversity Conservation and Adaptation to Climate Change: The Case of Hilltop Forests in Kitui, Kenya. In J. Mistry, \& A. Berardi (Eds.), Savannas and Dry Forests: Linking People with Nature (pp. 187-226). Ashgate.

Fraedrich, S. W. (2001). Seedborne Pathogens and Strategies to Eliminate and Reduce Their Presence on Tree Seeds. In Risks of Exotic Forest Pests and Their Impact on Trade, an International Online Workshop to Reduce Movement of Forest Pests with a Minimal Impact on Trade.

Franke, J. L., Geary, B., \& Meyer, S. E. (2014). Identification of the Infection Route of a Fusarium Seed Pathogen into Nondormant Bromus Tectorum Seeds. Phytopathology, 104, 1306-1313. https://doi.org/10.1094/PHYTO-03-14-0077-R

Gibreel, H. H., Kordofani, M. A. I., Warrag, E. I., \& Ahmed, H. O. (2013). Medicinal Value and Eco Taxonomy of the Flora of Blue Nile State-Sudan. Journal of Chemical and Pharmaceutical Research, 5, 36-43.

Gure, A., Wahlström, K., \& Stenlid, J. (2005). Pathogenicity of Seed-Associated Fungi to Podocarpus falcatus in Vitro. Forest Pathology, 35, 23-35. https://doi.org/10.1111/j.1439-0329.2004.00387.x

Hall, M., Al-Khulaidi, A. W., Miller, A. G., Scholte, P., \& Al-Qadasi, A. H. (2008). Arabia's Last Forests under Threat: Plant Biodiversity and Conservation in the Valley Forest of Jabal Bura (Yemen). Edinburgh Journal of Botany, 65, 113-135. 
https://doi.org/10.1017/S0960428608004976

ISTA (2004). International Rules for Seed Testing (Vol. 32, Supplement). In: Seed Science and Technology.

Khatun, A., Shamsi, S., \& Bashar, M. A. (2018). Diversity of Seed Borne Fungi Associated with Fourteen Varieties of Storage Cotton (Gossypium hirsutum L.) Seeds. Journal of Biodiversity Conservation and Bioresource Management, 4, 43-52.

Kitalyi, A., Musili, A., Suazo, J., \& Ogutu, F. (2002). Enclosures to Protect and Conserve. For Better Livelihood of the West Pokot Community. Technical Pamphlet No. 2.

Lezcano, J. C., Alonso, O., \& Navarro, M. (2015). Stored Seeds of Leucaena leucocephala cv. Peru., 38, 226-230.

Luna, T., \& Wilkinson, K. M. (2009). Chapter 7. Collecting, Processing, and Storing Seeds. In R. K. Dumroese, T. Luna, \& T. D. Landis (Eds.), Nursery Manual for Native Plants: A Guide for Tribal Nurseries_Volume 1: Nursery Management (pp. 113-131). Agriculture Handbook 730, U.S. Department of Agriculture, Forest Service.

Mosango, D. M. (2013). Terminalia brownie Fresen. In G. H. Schmelzer, \& A. Gurib-Fakim (Eds.), Prota 11(2): Medicinal Plants/Plantesmédicinales 2. PROTA.

Njoroge, G. N., Kaibui, I. M., Njenga, P. K., \& Odhiambo, P. O. (2010). Utilization of Priority Traditional Medicinal Plants and Local People's Knowledge on Their Conservation Status in Arid Lands of Kenya (Mwingi District). Journal of Ethnobiology and Ethnomedicine, 6, 22. https://doi.org/10.1186/1746-4269-6-22

Okeyo, M. M., Obwoyere, G. O., Makanji, D. L., Njuguna, J. W., \& Omondi, J. A. (2019). Fungal Diseases Attacking Floral Phenology of Terminaliabrownii in Drylands, Kenya. Poplar, 203, 5-11.

Okullo, J. B., \& Waithum, G. (2007). Diversity and Conservation of On-Farm Woody Plants by Field Types in Paromo Subcounty, Nebbi District, North-Western Uganda. African Journal of Ecology, 45, 59-66. https://doi.org/10.1111/j.1365-2028.2007.00859.x

Tsedaley, B. (2015). Review on Seed Health Tests and Detection Methods of Seedborne Diseases. Journal of Biology, Agriculture and Healthcare, 5, 176-184.

Gure, A., Wahlström, K., \& Stenlid, J. (2005). Pathogenicity of Seed-Associated Fungi to Podocarpusfalcatus in Vitro. Forest Pathology, 35, 23-35.

https://doi.org/10.1111/j.1439-0329.2004.00387.x3 